\title{
Challenges and Issues in relation to COVID-19 Contact Tracing Strategy in Mahara MOH area, Gampaha District
}

\author{
Dharmaratne GSK, Seralathan S, Paul Roshan G, Thennakoon TMCLB, Nishanthini N, Seralathan T.
}

\begin{abstract}
Introduction: COVID-19 was declared as public health emergency of international concern (PHEIC) by World Health Organization (WHO) on 30th of January 2020 as it was spreading all over the world. There was a rise in the number of cases of COVID-19 during the second wave in Sri Lanka. The epicenter was in Gampaha district. Ministry of Health embarked several strategies in preventive sector. Contact tracing is one of such strategy.
\end{abstract}

Objective: To identify the challenges and issues of contact tracing in Mahara Medical Officer of Health $(\mathrm{MOH})$ area in Gampaha district.

Methodology: This descriptive cross-sectional study was carried out in Mahara $\mathrm{MOH}$ area using qualitative and quantitative methods.

Results: The study revealed that a total number of 1532 cases were identified as contacts and they were subjected to Polymerase Chain Reaction (PCR) testing. The total number of positive cases was 575 out of 1532 contacts $(37.5 \%)$. Mahara $\mathrm{MOH}$ region had a relatively higher incidence rate during the study period compared to district and national figures.

Discussion: Public health staff faced many challenges during contact tracing. As contact tracing is a subjective procedure, when an index case is identified, the public health staff had to engage in various contact tracing processes during which, they faced difficulties in tracking the contacts. For example, some of them were not willing to reveal true primary contact details due to stigma and experienced that, giving false addresses added further burden to this challenging task. Recall bias had also affected contact tracing to a certain extent.

Conclusion \& Recommendation: Increasing public awareness through continuous public education would reduce the stigma of the disease and further strengthen the contact tracing.

Keywords: COVID-19, Sri Lanka, Challenges, Contact tracing, Preventive strategies

\section{Introduction}

Sri Lanka provides free health care to its citizens through well-demarcated preventive and curative sector arms (1). Preventive healthcare is provided through wellestablished Medical Officer of Health Units (MOHU) since 1925 (2), currently with $353 \mathrm{MOHU}$ (3) which are scattered all over 26 health districts of Sri Lanka (4). The Public Health Inspectors (PHII) in each $\mathrm{MOH}$ area working under $\mathrm{MOH}$ are trained to do contact tracing in the community.

Based on the circular of the Director General of Health Services (DGHS) issued on 04th December 2020 process of contact tracing has been changed (5). The individuals who were in contact with the index case are identified by contact tracing and quarantined at home setting rather than sending to quarantine centres $(5)(6)(7)$, and PCR testing is done based on the date of exposure and exposure level.

\section{Objectives}

1. To describe the process of contact tracing in Mahara $\mathrm{MOH}$ area

2. To determine the number of contacts traced during this period and the incidence of positive cases in MOH Mahara.

3. To identify the issues and challenges encountered during contact tracing process.

\section{Methodology}

This descriptive cross-sectional study was conducted during the period of 6th December 2020 to 31st January 2021 at Mahara MOHU.

In this study quantitative data was extracted from the registers maintained at Mahara MOHU and the qualitative data was gathered through means of field visits, direct observation, Key informant interviews and focus group discussions with the public health staff by a structured questionnaire. Administrative permission for the study was obtained from Regional Director of Health Services (RDHS) of Gampaha district. 


\section{Results}

Following the focus group discussions with relevant stakeholders, the process map of management of COVID-19 in the preventive sector was formulated (figure 1). With the contemporary updates and research findings, the health authorities updated the process map, accordingly.
Process mapping was formulated based on the process followed at Mahara $\mathrm{MOH}$ unit. It may vary from other $\mathrm{MOH}$ units in the district due to factors such as organizational structure, human resource capacity, geographical variation and trend of disease spread, etc. Formulation of contact tracing process map was done by focus group discussion with relevant staff.

Figure 1: Process map of Management of COVID-19 at MOHU Mahara

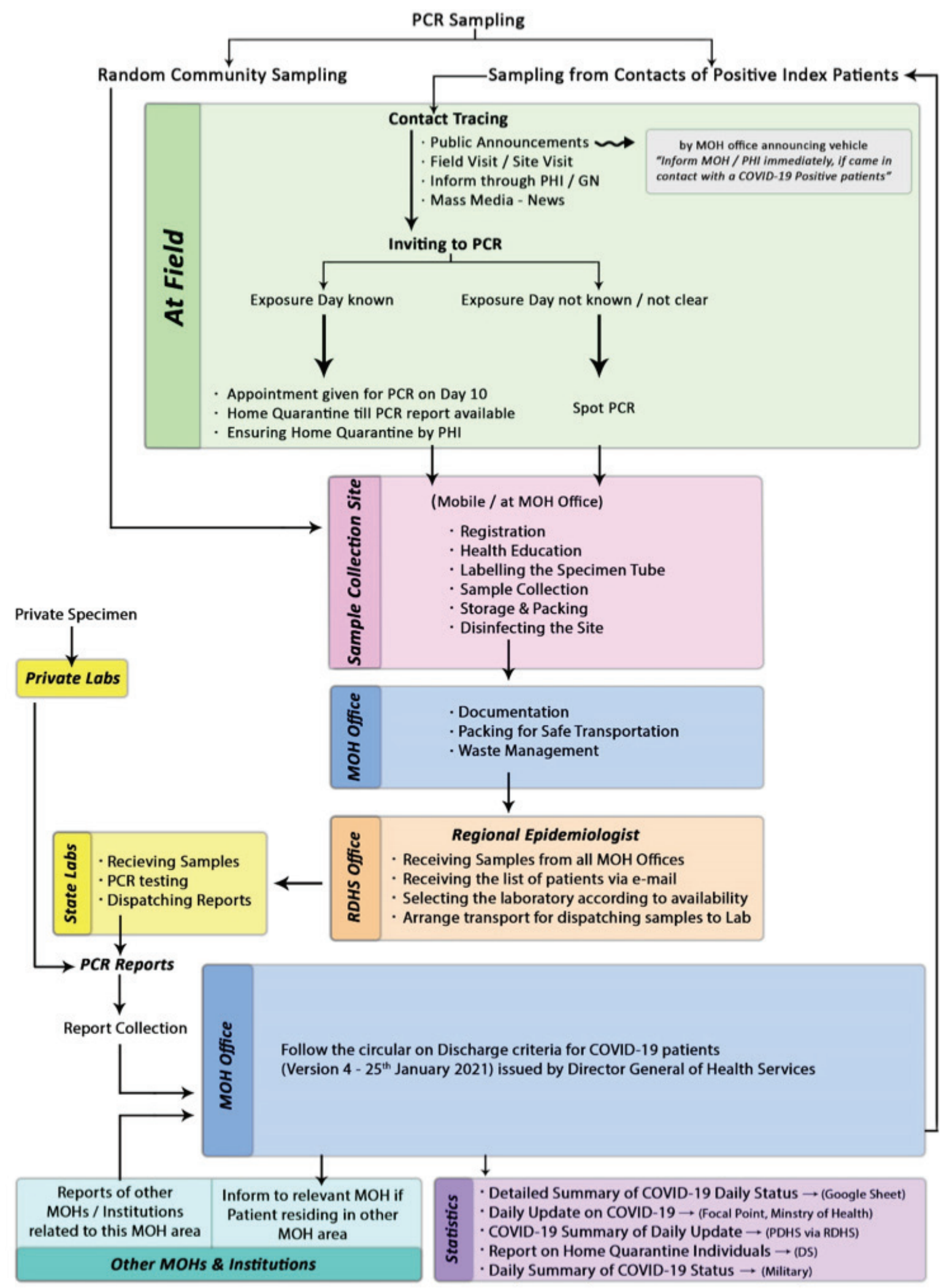


Along with the advancement in medical diagnosis, nucleic acid detection-based approaches have become a rapid and reliable technology for viral detection. Among nucleic acid tests, the PCR method is considered as the 'gold standard' for the detection of some viruses and is characterized by rapid detection, high sensitivity, and specificity (8).

As such, based on national level protocol, Mahara MOHU also used PCR tests to identify the infected cases. In order to do PCR, samples are collected from random community and from contacts of positive patients. The extracted data on PCR performance, positive cases detected among them along with the number of contacts and deaths is shown in table 1 .

Table 1: Weekly distribution of No. of PCR tests done, No. of positive cases, No. of contacts traced and deaths at Mahara MOHU

\begin{tabular}{llrrrr}
\hline Weeks & Date & $\begin{array}{r}\text { No. of PCR } \\
\text { Tests }\end{array}$ & $\begin{array}{r}\text { Total } \\
\text { Positive }\end{array}$ & $\begin{array}{r}\text { No. of } \\
\text { Contacts }\end{array}$ & Deaths \\
\hline Week 1 & $(06 / 12 / 2020-12 / 12 / 2020)$ & 426 & 23 & 129 & 1 \\
Week 2 & $(13 / 12 / 2020-19 / 12 / 2020)$ & 521 & 43 & 216 & 0 \\
Week 3 & $(20 / 12 / 2020-26 / 12 / 2020)$ & 290 & 42 & 317 & 2 \\
Week 4 & $(27 / 12 / 2020-02 / 01 / 2021)$ & 352 & 41 & 148 & 0 \\
Week 5 & $(03 / 01 / 2021-09 / 01 / 2021)$ & 666 & 60 & 159 & 0 \\
Week 6 & $(10 / 01 / 2021-16 / 01 / 2021)$ & 790 & 77 & 160 & 1 \\
Week 7 & $(17 / 01 / 2021-23 / 01 / 2021)$ & 424 & 151 & 181 & 1 \\
Week 8 & $(24 / 01 / 2021-31 / 01 / 2021)$ & 503 & 138 & 222 & 0 \\
\hline & Total & $\mathbf{3 9 7 2}$ & $\mathbf{5 7 5}$ & $\mathbf{1 5 3 2}$ & $\mathbf{5}$ \\
\hline
\end{tabular}

The table reveals that, during the study period 1532 cases were identified as contacts and they were subjected to PCR tests. A total number of 575 positive cases identified among 1532 traced contacts.

For comparison purposes, the PCR performance along with the number of positive cases and the number of contacts are graphically presented in figure 2 .

Figure 2: PCR performance and Contact tracing

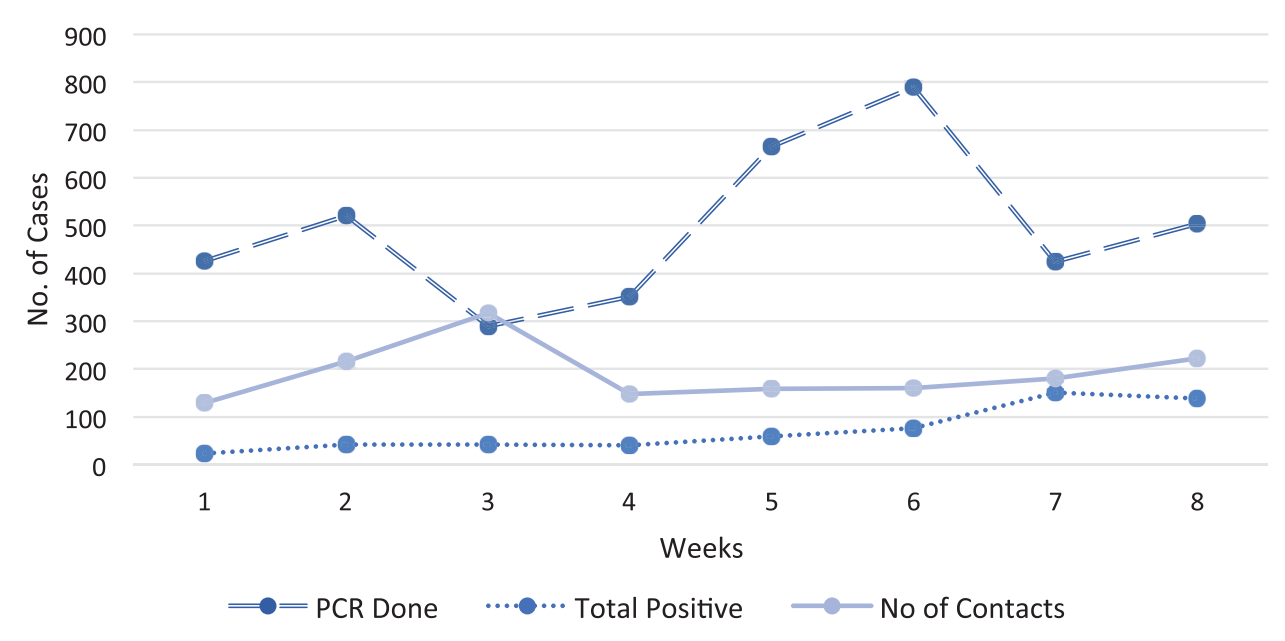


Summative values of above figures are calculated to determine the data on monthly basis (Table 2).

Table 2: Monthly distribution of No. of PCR tests done, No. of positive cases, No. of contacts traced and deaths

\begin{tabular}{lrrrr}
\hline Month & No. of PCR tests & Total Positive & No. ofContacts & Deaths \\
\hline December 2020 & 1589 & 138 & 782 & 3 \\
January 2021 & 2383 & 437 & 750 & 2 \\
\hline Total & $\mathbf{3 9 7 2}$ & $\mathbf{5 7 5}$ & $\mathbf{1 5 3 2}$ & $\mathbf{5}$ \\
\hline
\end{tabular}

From this data, incidence rate is calculated for each month of the study period and it is tabulated as shown in table 3 for comparison with district and national rates.

Table 3: Comparison of COVID-19 Incidence Rates of Mahara MOH with Gampaha district and national level

\begin{tabular}{lrrr}
\hline & $\begin{array}{r}\text { Incidence Rate* of } \\
\text { Mahara MOH area }\end{array}$ & $\begin{array}{r}\text { Incidence Rate* of } \\
\text { Gampaha District }\end{array}$ & $\begin{array}{r}\text { Incidence Rate* of } \\
\text { Sri Lanka }\end{array}$ \\
\hline December 2020 & 6.1 & 8 & 8.7 \\
January 2021 & 19 & 8.7 & 9 \\
\hline * per 10,000 population & & &
\end{tabular}

This reveals that, in comparison to district and national incidence rates (9) (10), the Mahara MOH area had a relatively higher incidence rate in January 2021. The Mahara MOH team has used the incidence rate to update the strategies and the process map accordingly.

Qualitative studies revealed the challenges encountered by grass root level staff during contact tracing. Understanding that, contact tracing is a subjective procedure staff faced many challenges to identify and to locate the contacts on time. During the Key informant interviews, PHIs revealed that the hardest challenge they faced is to trace primary and secondary contacts due to the social stigma and poor understanding of the disease by people. Hence, people tend to withhold information and given fabricated names and addresses which made the task a further burden.

Further, the following problems caused difficulties in locating the contacts

1) the lack of updated data on resident.

2) population migration due to employment and education needs.

3) Non availability of standard updated contact tracing protocols in the Ministry of Health. (This led the PHII to use their own checklists and criteria on risk assessment which contributed to the loss of uniformity in the contact tracing process)

Further, the study group came across the grievances shared by health staff due to severe distress. In this sense, health care workers are at a high risk of experiencing severe distress, burnout, and both mental and physical illness. In turn, this could affect outcomes, such as the quality of care provided by such institutions (11),(12),(13).

The main challenge in modelling contact tracing is the individual-based character of the process (14). Health workforce had to solely rely on the information provided by individuals. Reliability of the history provided is most of the time questionable.

\section{Discussion}

WHO emphasized the following strategies; testing, contact tracing, isolation, supported quarantine and quality care. Contact tracing, followed by treatment or isolation, is a key control measure in the battle against infectious diseases (15). As such, PCR testing and contact tracing are performed at the same time to augment the effect of COVID-19 management strategy. However, it was understood that the process might be changed depending on the circulars issued by DGHS, Ministry of Health from time to time. 
Stigma of the disease has been a burden for both the public and health care providers. When a disease is novel and leads to severe symptoms or death, fear, anxiety and limited knowledge about the disease may lead to stereotyping, discrimination, and labelling toward persons with the disease (16). For example, contact tracing by public announcement system has stigmatized the public of Mahara area and then the health authorities had to drop that plan with concern of confidentiality of patients.

Public health inspectors and their team had to solely rely on the information provided by index cases. Nonwillingness to reveal data and not understanding the importance of data has made the health staff to face further challenges in accurately tracing the contacts. Recall errors and exposures in public settings further impede contact identification (17).

Johannes Müller (14) describes the level of contact tracing in three levels:

- Individual level: Infected persons are diagnosed early, are isolated and receive medical attention.

- Population level: Transmission chains can be detected and stopped, which reduces the effective reproduction number.

- Medical/scientific level: By studying infectorinfectee pairs, one can learn about who infected whom in the outbreak.

As such, Mahara $\mathrm{MOH}$ incorporated all three levels of contact tracing to make the process more efficient. Intensified control measures, thoroughly training the workforce through in-service training, building their capacity, scaled up surveillance system, treatment modalities are some of the ingredients of success stories of preventive health arm of Sri Lanka. However, health authorities have faced difficulties in training the workforce regarding COVID-19 due to time constraints.

\section{Limitations}

This study has few limitations, such as a limited study setting and time constraints. So, the study could not be conducted in other MOHUs in the district. Also, abnormal field condition due to pandemic and lockdown has led difficulties for onsite field observations.

\section{Conclusion}

Key informant interviews and focus group discussions revealed that field-level staff faced challenges due to stigma of the disease and the subjective nature of the contact tracing process. Also, recall errors and nonwillingness of public to provide accurate data such as name and address has further added burden to this challenging task.

Increasing public awareness through continuous public education would reduce the stigma of the disease. Further to this, the introduction of mobile applications and data gathering at digital devices would reduce the recall errors and facilitates easy retrieval of accurate data.

However, extending similar studies in other MOHU or even other districts would help to identify challenges in different settings.

\section{Reference}

1. Health M of. Sri Lanka Essential Health Services Package. Ministry of Health; 2019.70 p.

2. MINISTRY OF HEALTH SRI LANKA. HISTORY OF MEDICINE IN SRI LANKA [Internet]. [cited 2021 Mar 16]. Available from: http://www.health. gov.lk/moh_final/english/others.php?spid=7

3. Ministry of Health Sri Lanka. Annual Health Bulletin 2018 [Internet]. 2018 [cited 2021 Mar 16]. Available from: http://www.health.gov.lk/moh_ final/english/public/elfinder/files/publications/ AHB/2020/AHB_2018.pdf

4. Ministry of Health Sri Lanka. Reorganising Primary Health Care in Sri Lanka Preserving our progress, preparing for our future [Internet]. Ministry of Health,Nutrition and Indigenous Medicine. 2018. 1-101 p. Available from: http://www.health.gov.lk

5. Ministry of Health Sri Lanka. Home quarantine circular [Internet]. Health Circular. 2020 [cited 2021 Mar 18]. Available from: http://rdhsofficegampaha. org/files/2020/12/Scan-06-12-2020.pdf

6. Presidential Secretariat Sri Lanka. Mechanism for observing home quarantine [Internet]. Circular No: PS/SPA/Circular/35/202. 2020 [cited 2021 Mar 18]. Available from: http://rdhsofficegampaha. org/files/2020/12/Home-quarantine-observationpresidential-sec.pdf

7. Ministry of Health Sri Lanka. Home Quarantine Guideline [Internet]. 2020 Nov [cited 2021 Mar 16]. Available from: https://www.epid.gov.lk/ web/images/pdf/Circulars/Corona_virus/Home_ Quarantine_Guidelines.pdf 
8. Tahamtan A, Ardebili A. Real-time RT-PCR in COVID-19 detection: issues affecting the results. Expert Rev Mol Diagn [Internet]. 2020 [cited 2021 Mar 15]; Available from: https://www.tandfonline. com/action/journalInformation?journalCode $=\mathrm{ie}$ ro20

9. Health Promotion Bureau Sri Lanka. HPB I Live updates on New Coronavirus (COVID-19) outbreak [Internet]. [cited 2021 Mar 18]. Available from: https://www.hpb.health.gov.lk/en

10. Gampaha RDHS Office. COVID19 Statistics Rdhs Office Gampaha [Internet]. [cited 2021 Mar 18]. Available from: http://rdhsofficegampaha.org/ covid19-statistics/

11. Portoghese I, Galletta M, Coppola RC, Finco G, Campagna M. Burnout and workload among health care workers: The moderating role of job control. Saf Health Work. 2014 Sep 1;5(3):152-7.

12. Marine A, Ruotsalainen J, Serra C, Verbeek J. Preventing occupational stress in healthcare workers [Internet]. Cochrane Database of Systematic Reviews. John Wiley and Sons Ltd; 2006 [cited 2021 Mar 15]. Available from: https:// pubmed.ncbi.nlm.nih.gov/17054155/

13. Wu S, Li H, Zhu W, Lin S, Chai W, Wang X. Effect of work stressors, personal strain, and coping resources on burnout in Chinese medical professionals: A structural equation model. Ind Health [Internet]. 2012 [cited 2021 Mar 15];50(4):279-87. Available from: https://pubmed.ncbi.nlm.nih.gov/22673361/

14. Müller J, Kretzschmar M. Contact tracing - Old models and new challenges. Infect Dis Model. 2021 Jan 1;6:222-31.

15. Eames KTD, Keeling MJ. Contact tracing and disease control. Proc R Soc B Biol Sci [Internet]. 2003 Dec 22 [cited 2021 Mar 15];270(1533):256571. Available from: https://pubmed.ncbi.nlm.nih. gov/14728778/
16. Turner-Musa J, Ajayi O, Kemp L. Examining Social Determinants of Health, Stigma, and COVID-19 Disparities. Healthcare [Internet]. 2020 Jun 12 [cited 2021 Mar 15];8(2):168. Available from: https://pubmed.ncbi.nlm.nih.gov/32545647/

17. Kleinman RA, Merkel C. Digital contact tracing for covid-19. CMAJ [Internet]. 2020 Jun 15 [cited 2021 Mar 15];192(24):E653-6. Available from: https://pubmed.ncbi.nlm.nih.gov/32461324/ 